\title{
Temporal trends and differences in mortality at trauma centres across Ontario from 2005 to 2011: a retrospective cohort study
}

\author{
David Gomez MD PhD, Aziz S. Alali MD PhD, Barbara Haas MD PhD, Wei Xiong MSc, \\ Homer Tien MD MSc, Avery B. Nathens MD PhD
}

Abstract

Background: Care in a trauma centre is associated with significant reductions in mortality after severe injury. However, emerging evidence suggests that outcomes across similarly accredited trauma centres are not equivalent, even after adjusting for case-mix. The primary objective of this analysis was to evaluate secular trends in overall mortality at trauma centres. Secondarily, we explored trauma centre-specific mortality to determine the extent of variation between centres.

Methods: Data on 26421 adults ( $\geq 18 \mathrm{yr}$ ) admitted to a trauma centre between 2005 and 2011 were derived from the Ontario Trauma Registry. We used generalized estimating equations to calculate in-hospital mortality over time and hierarchical models to estimate trauma centre-specific mortality. To quantify variability between centres, we calculated median odds ratios. Adjusted odds of death were calculated for each trauma centre to identify those with higher than expected, average and lower than expected mortality.

Results: Overall mortality at trauma centres decreased from $13.2 \%$ in 2005 to $11.2 \%$ in 2009 . After adjusting for case mix, the odds of death decreased by approximately $3 \%$ a year (95\% confidence interval $0 \%-5 \%$ ). Trauma centre-specific mortality ranged from $11.4 \%$ to $13.1 \%$. After adjusting for case mix, differences in trauma centre-specific mortality were observed (median odds ratio $=1.25$ ), suggesting that the odds of dying could be 1.25-fold greater if the same patient was admitted to 1 randomly selected trauma centre as opposed to another. Differences were most pronounced for patients with isolated head injuries and among older patients as evidenced by higher median odds ratios and the number of outliers.

Interpretation: We observed a significant improvement over time in the mortality of severely injured patients cared for at Ontario's trauma centres. However, considerable differences in trauma centre-specific mortality were observed. Differences were most pronounced among older injured patients and those with isolated traumatic brain injury. System-wide performance improvement initiatives should target these subgroups.

I

n Canada, injury is an important public health concern. It is the leading cause of death in those 44 years of age and - younger and the fifth overall leading cause of death. ${ }^{1}$ In 2004 , over 3 million visits were made to emergency departments because of injuries and over 200000 of these patients required admission to hospital. These injuries resulted in over 13000 deaths and over 60000 partial or permanent disabilities. ${ }^{2}$ In Ontario, 1 out of every 4 emergency department visits and 1 out of every 17 hospital admissions in 2002-2003 were injury-related. ${ }^{3}$

In June 1990, Ontario's Ministry of Health and Long-term Care designated 9 hospitals as adult trauma centres. The designation was accompanied by funding for infrastructure, 24-hour physician coverage and incremental funding. ${ }^{4}$ In addition, in 2006, trauma centres underwent an initial process of voluntary external accreditation by the Trauma Association of Canada, which evaluated the availability of resources and personnel essential for caring for injured patients.

Large prospective studies have shown that care in a trauma centre is associated with a $25 \%$ lower 1-year mortality, as well as improved functional outcomes after severe injury, compared with care at similarly resourced non-trauma centres. ${ }^{5,6}$ However, it is evident that outcomes across similarly accredited trauma centres are not equivalent, even after considering differences in case mix. ${ }^{7-9}$

Competing interests: None declared.

This article has been peer reviewed.

Correspondence to: David Gomez, gomezjaramid@smh.ca CMAJ Open 2014.DOI:10.9778/cmajo.20140007 
The primary objective of this analysis was to evaluate secular trends in mortality in trauma centres among severely injured adults. Secondarily, we explored the extent of variation in mortality across trauma centres with a view to guiding system-wide performance improvement.

\section{Methods}

\section{Setting and data source}

Nine designated adult trauma centres serve Ontario's 13 million residents. They are located in Windsor, London, Hamilton, Ottawa, Kingston, Sudbury, Thunder Bay and Toronto. Most (7 of 9) underwent external accreditation by the Trauma Association of Canada in 2006; thus, most have similar human and physical resources required for the care of injured patients. ${ }^{10}$

Data were derived from the Ontario Trauma Registry Comprehensive Data Set (OTR-CDS). The OTR-CDS contains detailed demographic, diagnostic and procedural data on patients admitted to hospital with major trauma via trauma centres in Ontario. In the registry, major trauma is defined by an external cause of injury code in the W78 to Y98 range in the International Statistical Classification of Diseases and Related Health Problems, 10th rev (ICD-10), World Health Organization, 1992, and an Injury Severity Score of 12 or more. ${ }^{11}$

Case ascertainment in the OTR-CDS is assumed to be high as trauma centre funding is aligned with patient volumes. The OTR-CDS is not a population-based data set. All data in it are de-identified at both the patient and facility level; for this reason, we represented trauma centres by a number (1-9). However, unique encrypted patient and facility identifiers are present.

This project was reviewed and approved by the Research Ethics Board of Sunnybrook Health Sciences Centre.

\section{Assembly of study cohort}

We identified adult patients $\geq 18$ years of age who were admitted to 1 of Ontario's 9 adult trauma centres between Apr. 1, 2005, and Mar. 30, 2011. For the purpose of this study, we included only those with mechanical sources of injury and excluded patients admitted with poisoning, suffocation, drowning, overexertion, environmental causes and burns. Mechanisms of injury were derived based on the Centers for Disease Control and Prevention's ICD-10 external cause of injury matrix. ${ }^{12}$ Our main outcome measure was in-hospital mortality.

Patients without signs of life on arrival (i.e., heart rate $=0$, systolic blood pressure $=0$ and motor component of the Glasgow Coma Scale $[\mathrm{GCS}]=1$ ) were also excluded in the belief that they were unable to be resuscitated, regardless of quality of care received. ${ }^{13}$

\section{Patient subgroups}

Patients were divided into 5 distinct injury cohorts that challenge different components of trauma centre care: penetrating truncal injury (penetrating mechanism of injury in the neck, chest or abdomen and Abbreviated Injury Scale score [AIS] $\geq 3$ ); shock (systolic blood pressure in the emergency department $\leq 90 \mathrm{~mm} \mathrm{Hg}$ ); blunt multisystem injury (blunt mechanism of injury and AIS $\geq 3$ in at least 2 body regions); older patients
( $\geq 65 \mathrm{yr}$ ); and isolated traumatic brain injury (head AIS $\geq 4$ or head AIS $=3$, motor component of the GCS $\leq 4$ and AIS $\leq 2$ in any other body region). ${ }^{14,15}$ Patients were not identified with isolated traumatic brain injury if their only qualifying head injury code was a scalp, internal carotid artery, vertebral artery or bony injury. Patients may have been included in more than 1 cohort (e.g., patient with penetrating truncal injury in shock).

\section{Evaluation of secular trends in overall mortality at trauma centres}

We used generalized estimating equations to evaluate secular trends in in-hospital mortality after adjusting for changes in patient characteristics over the 7 years of study. The following covariables were included in adjusted analyses: study year, patient sex and age, injury characteristics (mechanism of injury, AIS by body region), vital signs on arrival (heart rate, systolic blood pressure and motor component of the GCS) and transfer status (Box 1).

Survival risk ratios based on AIS scores were calculated for each patient, by subgroup, and included in our adjusted analysis as an additional continuous covariable. A survival risk ratio is a database-specific point estimate of survival and is defined as the number of patients who survived the AIS-coded injury divided by the total number of patients who sustained the same injury. ${ }^{16}$ These ratios range from 0 to 1 , with a lower score

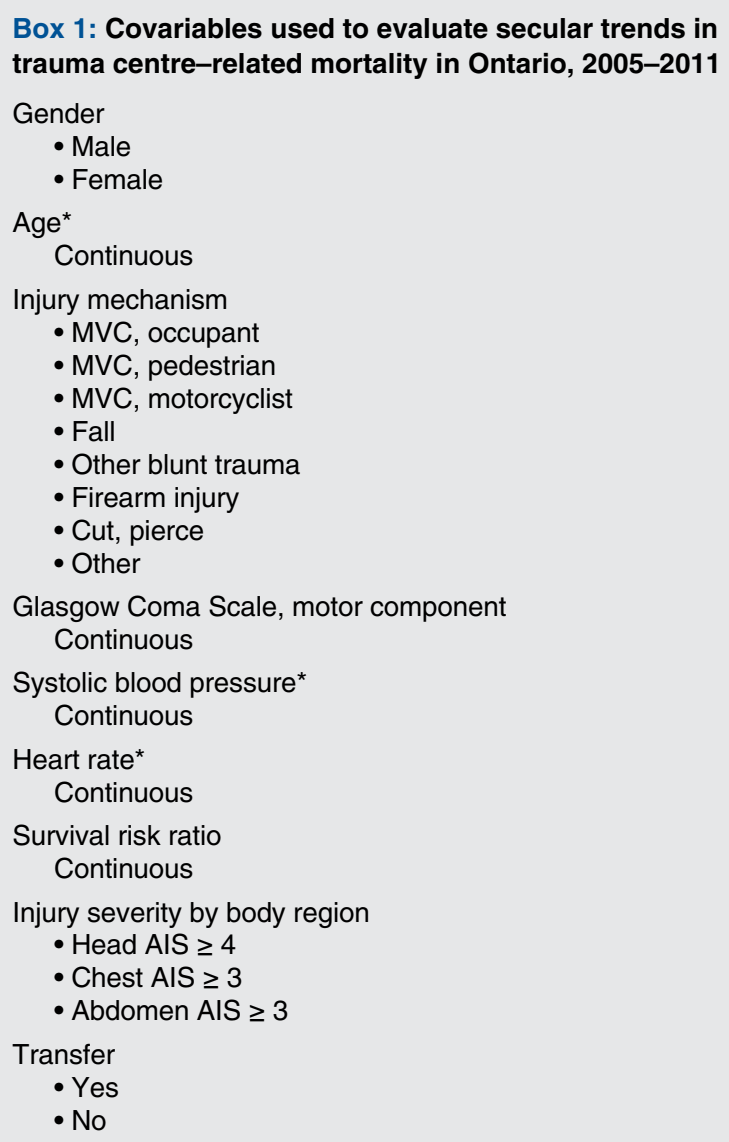

Note: AIS = Abbreviated Injury Scale, MVC = motor vehicle collision ${ }^{\star}$ Data were fitted differently for each model. 
representing lower probability of survival. We applied a traditional worst-injury approach to calculating survival risk ratio, in which the smallest (worst) ratio is selected for each patient. Although survival risk ratios are estimates of true survival and are population-specific, they have been shown to further explain variance and offer better discrimination compared with injury scoring systems, such as the Injury Severity Score. ${ }^{16}$

\section{Evaluation of trauma centre-specific mortality}

In addition to evaluating changes in overall mortality at trauma centres over time, we explored trauma centre-specific rates to determine the extent of variation across centres. To adjust for differences in case mix among centres, we used several hierarchical logistic regression models to estimate trauma centrespecific risk-adjusted mortality, overall and for each of the 5 patient subgroups. Patients were considered the lower-level units and trauma centres the higher-level units. Patient-level covariables were age, sex, mechanism of injury, survival risk ratio, severe injury by body region, motor component of GCS, systolic blood pressure, heart rate and transfer status (Box 1). We used hierarchical models because they facilitate the exploration of variability across different levels of nested data. ${ }^{17,18}$

To quantify variability among trauma centres, we calculated the median odds ratio, which can be interpreted as the adjusted odds of dying if the same patient was admitted to 2 different randomly selected hospitals. It always has a value of 1 or more because it compares a higher- with a lower-ranked hospital. It estimates unexplained heterogeneity among different centres after adjusting for patient-level characteristics. ${ }^{17}$ Variability was assessed for the overall cohort and for each patient subgroup.

To further characterize variability among centres, we calculated adjusted odds ratios of death and their $95 \%$ confidence intervals (CIs). Trauma centre-specific odds ratios of death represent the likelihood of death at each hospital relative to the overall average for all centres. ${ }^{19} \mathrm{~A}$ trauma centre has a lower than expected mortality if the upper limit of its $95 \% \mathrm{CI}$ is $<1$, representing a significantly lower odds of death. If the lower limit of the $95 \% \mathrm{CI}$ is $>1$, the centre has a higher than expected mortality and patients cared for in that centre have a significantly higher odds of death than if cared for in the average centre.

\section{Statistical analysis}

We carried out sensitivity analyses excluding transfer patients. We used multiple imputation to address missing values for heart rate (5\%), systolic blood pressure (5\%) and motor component of GCS $(13 \%) .{ }^{20}$ For each model, we estimated discrimination using the $c$-statistic and assessed calibration using observed-versus-predicted outcome plots. In all analyses, $p<0.05$ was considered significant. All data were analyzed using SAS (v. 9.3, SAS Institute, Cary, NC).

\section{Results}

We identified 26421 adult injured patients who received care at 1 of Ontario's trauma centres between Apr. 1, 2005, and Mar. 30, 2011. Most patients were male and the mean age was 52 years (standard deviation 22). Most patients were injured as a result of a motor vehicle collision (44.9\%) or a fall (41.1\%). Severe multisystem injuries were common; almost half of the patients had an Injury Severity Score $\geq 25$ (median 24, interquartile range 16-27). Baseline characteristics of the entire cohort and patient subgroups are shown in Table 1.

\section{Secular trends in overall mortality at trauma centres}

During the study period, the volume of patients per year increased by $15.0 \%$, from 3449 patients in 2005 to 4051 in 2011 (Table 2). Patient and injury characteristics and the distribution of patient subgroups also changed over time: the proportion of older ( $\geq 65 \mathrm{yr}$ ) injured patients, patients with isolated traumatic brain injury, and patients with blunt multisystem injuries increased significantly during the study interval. Injury severity, as measured by the proportion of patients with an Injury Severity Score $\geq 25$, was unchanged over time.

Overall in-hospital mortality was $12.0 \%(n=3174)$; however, it decreased from $13.2 \%(n=457)$ in 2005 to $11.2 \%$ $(n=453)$ in 2011 (Figure 1). The overall adjusted odds of death decreased by approximately $3 \%$ a year (odds ratio 0.97 , 95\% CI 0.95-1.00). Similarly, the adjusted odds of death for most patient subgroups also decreased during the study period, by $5 \%$ to $10 \%$ a year.

\section{Trauma centre-specific mortality}

Crude mortality ranged from $11.4 \%$ to $13.1 \%$ among the trauma centres $(p=0.21)$. After adjusting for case mix, the median odds ratio for trauma-related death among hospitals was 1.25 , suggesting that the odds of dying after injury could be 1.25 -fold greater if the same patient was admitted to 1 randomly selected trauma centre as opposed to another. Furthermore, differences were evident among centre-specific odds ratios of death compared with the overall average, as 1 centre was identified as having significantly lower mortality compared with the overall average. Conversely, 1 centre had a significantly higher than expected mortality. The remaining 7 trauma centres had expected rates of mortality given their case mixes.

Similar differences were identified across various patient subgroups, with median odds ratios ranging from as low as 1.21 among patients experiencing shock to as high as 1.47 among the subgroup with isolated traumatic brain injury. As expected, the greatest number of outliers (i.e., centres with higher or lower than expected mortality) occurred among the patient subgroups with the highest median odds ratios. For the older subgroup, 2 centres had significantly lower than expected mortality and 2 had significantly higher than expected mortality. Furthermore, for the subgroup with isolated traumatic brain injury, 1 centre had significantly lower than expected mortality and 3 centres had significantly higher than expected mortality. No centre was characterized as having a higher or lower than expected mortality in subgroups with shock or penetrating truncal injury (Table 3 ).

After excluding transfer patients from our analyses, the number of outliers decreased, particularly among the group with isolated traumatic brain injury. The direction and size of the effect remained similar, however, suggesting that the loss of outlier status might reflect a reduction of up to $50 \%$ in sample (Table 4). 


\section{Interpretation}

Traumatic injury is a major cause of death and disability in Canada. ${ }^{1-3}$ Substantial resources have been allocated to regionalization of care and designated trauma centres. ${ }^{4}$ In the United States, care in such trauma centres has been associated with a $25 \%$ reduction in 1-year mortality for patients with severe injuries compared with those receiving care in a similarly resourced non-trauma centre. ${ }^{5}$ Thus, it is important to evaluate the outcomes of severely injured patients

\begin{tabular}{|c|c|c|c|c|c|c|c|}
\hline \multirow{3}{*}{$\begin{array}{l}\text { Characteristic } \\
\text { Male }\end{array}$} & \multirow{2}{*}{\multicolumn{2}{|c|}{$\begin{array}{c}\text { Overall } \\
n=26421\end{array}$}} & \multicolumn{5}{|c|}{ Patient subgroup, no. $(\%)^{*}$} \\
\hline & & & \multirow{2}{*}{$\begin{array}{c}\begin{array}{c}\text { Penetrating } \\
\text { truncal injury } \\
n=1032\end{array} \\
937(91.7)\end{array}$} & $\begin{array}{c}\text { Shock in ED } \\
n=1230\end{array}$ & $\begin{array}{c}\text { Blunt } \\
\text { multisystem } \\
\text { injury } \\
n=9942\end{array}$ & $\begin{array}{c}\text { Older } \\
(\geq 65 \mathrm{yr}) \\
n=8715\end{array}$ & $\begin{array}{c}\text { Isolated } \\
\text { traumatic brain } \\
\text { injury } \\
n=9167\end{array}$ \\
\hline & 18751 & (71.4) & & $848 \quad(68.9)$ & $8852(89.0)$ & $5259(60.3)$ & $6401 \quad(69.8)$ \\
\hline \multicolumn{8}{|l|}{ Age } \\
\hline Mean, yr (SD) & & (22) & 32 (14) & $49(21)$ & $47(20)$ & $78 \quad(8)$ & $62(21)$ \\
\hline$\geq 65$ & 8715 & (33.2) & $38(3.7)$ & $322(26.2)$ & $2262(22.7)$ & $8715(100)$ & $4923(53.7)$ \\
\hline \multicolumn{8}{|l|}{ Injury mechanism } \\
\hline MVC, occupant & 9886 & $(37.7)$ & $0 \quad(0)$ & $616(50.0)$ & $6008(60.4)$ & $1827(20.9)$ & $1085 \quad(11.8)$ \\
\hline MVC, pedestrian & 585 & $(2.2)$ & $0 \quad(0)$ & $18 \quad(1.5)$ & $198 \quad(1.9)$ & $116 \quad(1.3)$ & $190 \quad(2.0)$ \\
\hline MVC, motorcyclist & 1323 & $(5.0)$ & $0 \quad(0)$ & $50 \quad(4.1)$ & $561 \quad(5.6)$ & $129 \quad(1.5)$ & $215 \quad$ (2.3) \\
\hline Fall & 10874 & $(41.4)$ & $0 \quad(0)$ & 298 (24.2) & $2489(25.0)$ & $6259(71.8)$ & $6320 \quad(68.9)$ \\
\hline Other blunt trauma & 1854 & (7.1) & $0 \quad(0)$ & $60 \quad(4.9)$ & $474 \quad(4.8)$ & $203 \quad(2.3)$ & $962 \quad(10.5)$ \\
\hline Firearm injury & 518 & (1.9) & $362(35.1)$ & $64 \quad(5.2)$ & $0 \quad(0)$ & $20 \quad(0.2)$ & $78 \quad(0.8)$ \\
\hline Cut, pierce & 761 & $(2.9)$ & $670(64.9)$ & $92 \quad(7.5)$ & $0 \quad(0)$ & $37 \quad(0.4)$ & $37 \quad(0.4)$ \\
\hline Other & 620 & $(2.4)$ & $0 \quad(0)$ & $32 \quad(2.6)$ & $212 \quad(2.1)$ & $124 \quad(1.4)$ & (3.0) \\
\hline \multicolumn{8}{|l|}{ Injury severity score } \\
\hline Median (IQR) & & $(16-27)$ & $19(17-26)$ & $29(21-41)$ & $29(22-38)$ & $25(16-25)$ & $25(16-25)$ \\
\hline$\geq 25$ & 12608 & (47.7) & $398(38.6)$ & $849(69.0)$ & 7019 (70.6) & $4504(51.7)$ & $4618(50.4)$ \\
\hline \multicolumn{8}{|l|}{$\begin{array}{l}\text { Motor component of } \\
\text { GCS }\end{array}$} \\
\hline $5-6$ & 21666 & $(82.0)$ & $860(83.3)$ & 770 (62.6) & $7665 \quad(77.1)$ & $7366(84.5)$ & $7265 \quad(79.2)$ \\
\hline $3-4$ & 2306 & $(8.7)$ & $53 \quad(5.1)$ & $144 \quad(11.7)$ & $961 \quad(9.7)$ & $784 \quad(8.9)$ & $1027 \quad(11.2)$ \\
\hline $1-2$ & 2449 & $(9.3)$ & $119(11.5)$ & $316(25.7)$ & 1316 & $565 \quad(6.4)$ & (9.5) \\
\hline $\begin{array}{l}\text { Shock in ED } \\
\text { (SBP } \leq 90 \mathrm{~mm} \mathrm{Hg} \text { ) }\end{array}$ & 1230 & $(4.7)$ & $131(12.7)$ & $1230(100)$ & $725 \quad(7.3)$ & $322 \quad(3.7)$ & (1.7) \\
\hline \multicolumn{8}{|l|}{ Severe injury (AIS $\geq 3$ ) } \\
\hline Head & 15198 & $(57.5)$ & $58 \quad(5.6)$ & $684(55.6)$ & $5473(55.0)$ & $5454(62.6)$ & $9167(100)$ \\
\hline Chest & 10088 & (38.2) & 769 (74.5) & 547 (44.5) & $6794 \quad(68.3)$ & $2841(32.6)$ & $0 \quad(0)$ \\
\hline Abdomen & 2646 & $(10.0)$ & 454 (43.9) & $206(16.7)$ & $1834(18.4)$ & $650 \quad(7.5)$ & (0) \\
\hline Lower extremity & 5510 & (20.8) & $67 \quad(6.5)$ & 305 (24.8) & $4073(40.9)$ & 1531 (17.6) & $0 \quad(0)$ \\
\hline $\begin{array}{l}\text { Transfers from outside } \\
\text { institutions }\end{array}$ & 12406 & $(46.9)$ & $245(23.7)$ & $444(36.1)$ & $4726 \quad(47.5)$ & $4188(48.1)$ & $4435 \quad(48.4)$ \\
\hline \multicolumn{8}{|l|}{ Mortality } \\
\hline In-hospital & 3174 & (12.0) & $116 \quad(11.2)$ & 410 (33.3) & 1303 & $1754(20.1)$ & $1475 \quad(16.1)$ \\
\hline Died in ED & 368 & (1.4) & $45 \quad(4.4)$ & $106 \quad(8.6)$ & $150 \quad(1.5)$ & $141 \quad(1.6)$ & (1.3) \\
\hline
\end{tabular}

Note: AIS = Abbreviated Injury Scale, ED = emergency department, GCS = Glasgow Coma Scale, IQR = interquartile range, $\mathrm{MVC}=$ motor vehicle collision, $\mathrm{SBP}=$ systolic blood pressure, $\mathrm{SD}=$ standard deviation.

*Unless otherwise indicated. 


\section{OPEN}

Research

admitted to trauma centres. In addition, exploring variation in outcomes across centres may guide system-wide performance improvement.

This study has 3 key findings. First, the risk-adjusted odds of death among severely injured patients who received care at trauma centres in Ontario decreased by approximately 3\% a year during the study period. Second, we identified significant differences in mortality among trauma centres. Such differences persisted after adjustment for case mix and after accounting for correlation of patients' outcomes at different trauma centres. For example, the odds of death could be 1.25 -fold greater if the same patient was admitted to 1 randomly selected trauma centre as opposed to another. Third, we found that differences in risk-adjusted mortality among trauma centres were most pronounced in older patients and those with isolated head injuries.

Despite the observed decrease in mortality among patients treated in trauma centres over the study period, we believe that we have identified important opportunities for systemwide performance improvement. Older patients and those

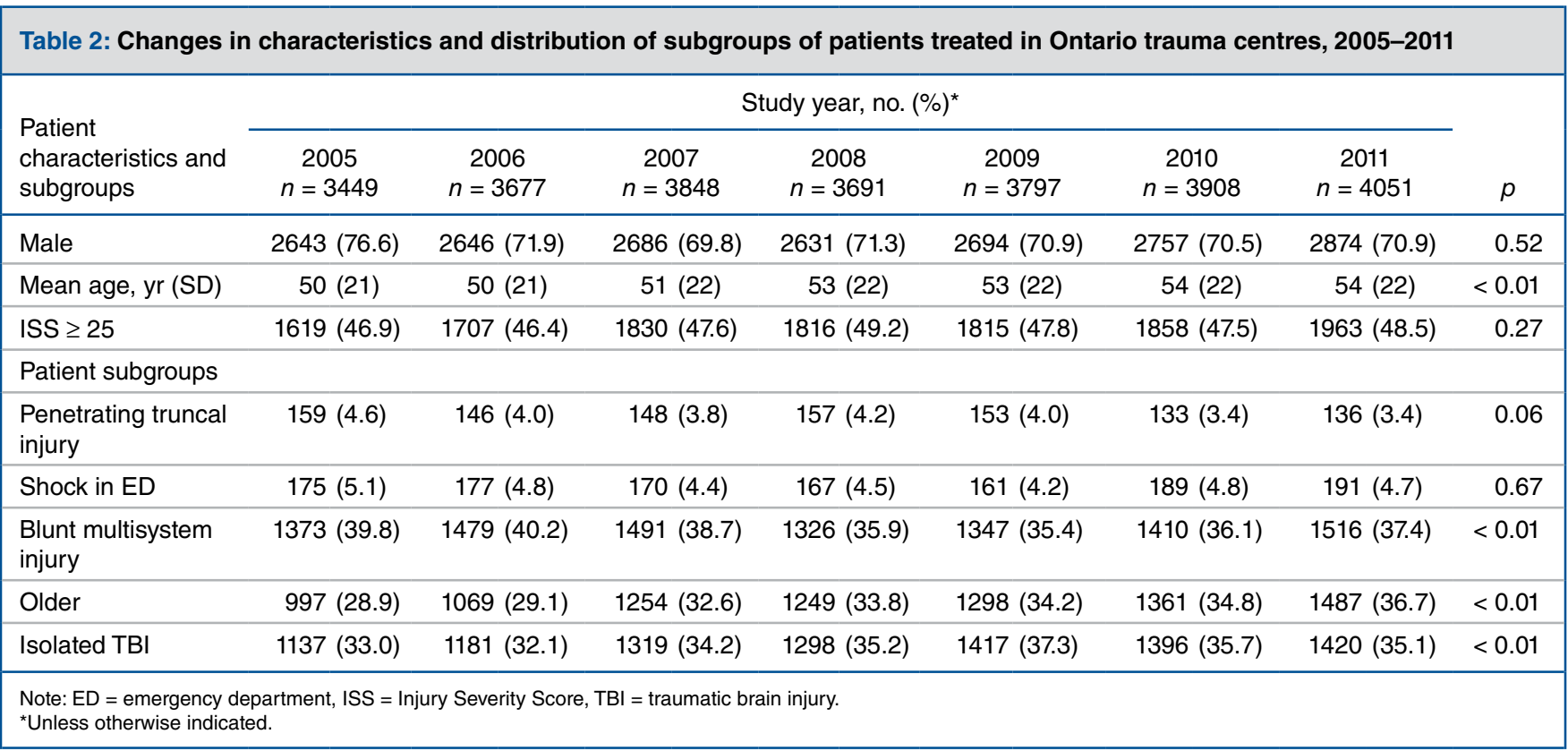

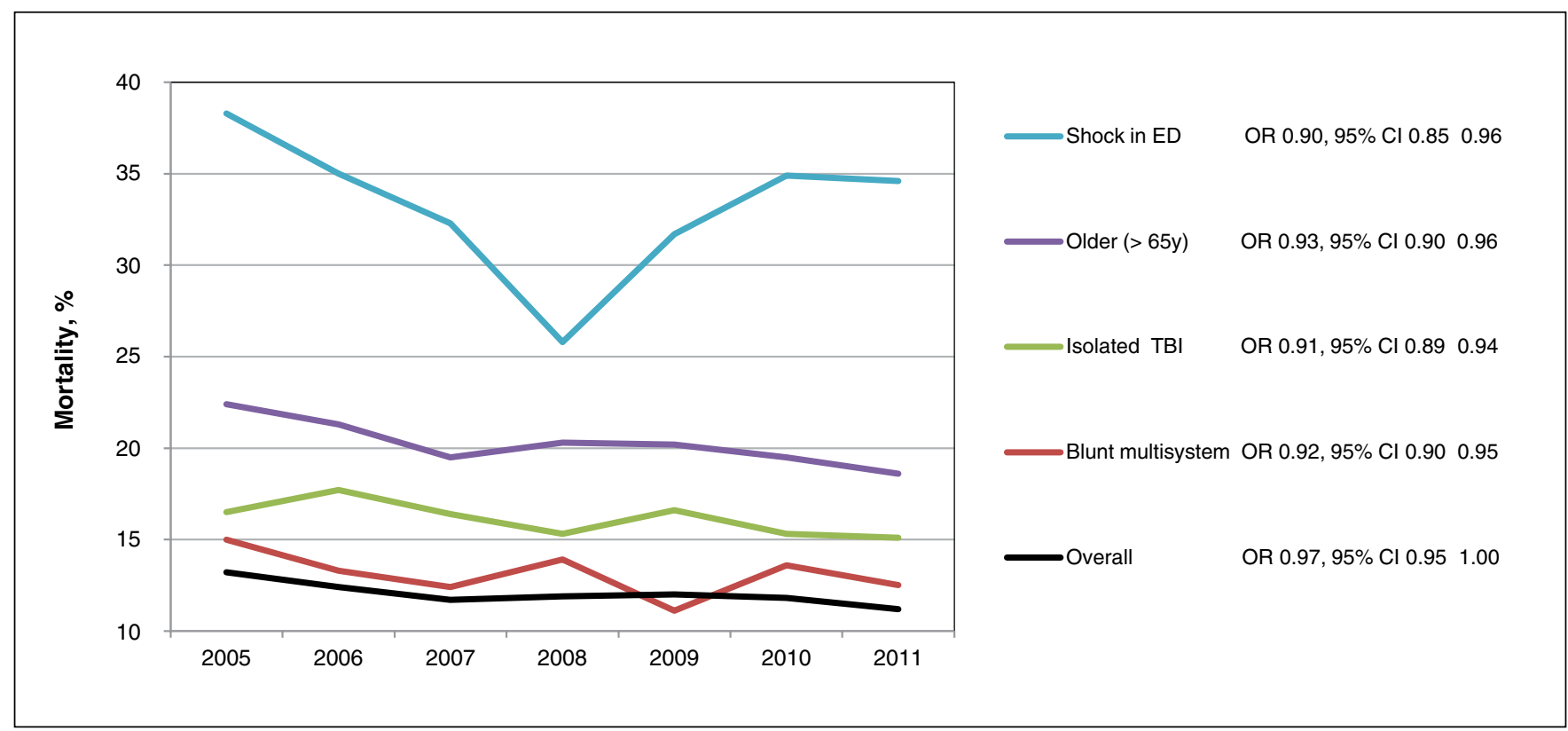

Figure 1: Secular trends in Ontario trauma centre mortality, overall and among patient subgroups, 2005-2011. Odds ratios represent the adjusted likelihood of death by 1-year increments over the study period. 
with isolated traumatic brain injury were the subgroups among which the greatest differences in trauma centre-specific mortality occurred. Factors that may explain such inter-hospital differences in risk-adjusted mortality of these patient subgroups include differences in structures and processes of care for these patients, ${ }^{21-23}$ variation in physicians' perceptions of long-term prognosis ${ }^{24}$ and variable practice patterns for withdrawal of life-sustaining interventions. ${ }^{25,26}$ Further research on these patient subgroups is needed to highlight the sources of the differences in risk-adjusted mortality between

Table 3: Differences in trauma centre-specific adjusted mortality rates, overall and across patient subgroups in Ontario, 20052011*

\begin{tabular}{|c|c|c|c|c|c|c|}
\hline \multirow[b]{2}{*}{$\begin{array}{l}\text { Trauma } \\
\text { centre }\end{array}$} & \multirow{2}{*}{$\begin{array}{l}\text { Overall, adjusted } \dagger \\
\text { mortality rate } \\
(95 \% \mathrm{Cl})\end{array}$} & \multicolumn{5}{|c|}{ Patient subgroup, adjusted $†$ mortality rate $(95 \% \mathrm{Cl})$} \\
\hline & & Shock & $\begin{array}{l}\text { Penetrating } \\
\text { truncal injury }\end{array}$ & $\begin{array}{l}\text { Blunt multisystem } \\
\text { injury }\end{array}$ & Older ( $\geq 65 \mathrm{yr})$ & $\begin{array}{c}\text { Isolated severe } \\
\text { TBI }\end{array}$ \\
\hline 1 & $0.72(0.60-0.87)$ & $0.81(0.60-1.09)$ & $1.25(0.83-1.89)$ & $0.74(0.56-0.98)$ & $0.72(0.54-0.96)$ & $0.46(0.33-0.64)$ \\
\hline 2 & $0.87(0.69-1.12)$ & $0.91(0.63-1.30)$ & $1.00(0.58-1.73)$ & $0.74(0.47-1.16)$ & $0.58(0.39-0.85)$ & $0.73(0.49-1.10)$ \\
\hline 3 & $0.87(0.70-1.08)$ & $0.99(0.70-1.41)$ & $0.84(0.49-1.44)$ & $1.20(0.83-1.75)$ & $0.95(0.69-1.29)$ & $1.05(0.74-1.50)$ \\
\hline 4 & $0.87(0.69-1.01)$ & $1.09(0.76-1.55)$ & $0.98(0.57-1.68)$ & $0.81(0.54-1.21)$ & $0.84(0.60-1.18)$ & $0.82(0.56-1.19)$ \\
\hline 5 & $0.89(0.73-1.07)$ & $1.05(0.77-1.43)$ & $0.90(0.58-1.39)$ & $0.79(0.58-1.07)$ & $0.84(0.63-1.12)$ & $0.79(0.58-1.09)$ \\
\hline 6 & $1.18(0.98-1.43)$ & $1.14(0.82-1.57)$ & $1.16(0.70-1.93)$ & $1.18(0.87-1.60)$ & $1.19(0.90-1.56)$ & $1.43(1.05-1.94)$ \\
\hline 7 & $1.17(0.97-1.41)$ & $1.08(0.79-1.48)$ & $1.14(0.69-1.88)$ & $1.40(1.04-1.87)$ & $1.30(0.98-1.72)$ & $1.39(1.01-1.90)$ \\
\hline 8 & $1.23(0.99-1.53)$ & $1.05(0.75-1.48)$ & $0.95(0.55-1.62)$ & $0.82(0.57-1.19)$ & $1.51(1.11-2.08)$ & $1.46(1.02-2.09)$ \\
\hline 9 & $1.38(1.14-1.68)$ & $0.93(0.67-1.28)$ & $0.86(0.51-1.43)$ & $1.75(1.29-2.38)$ & $1.52(1.14-2.03)$ & $1.55(1.11-2.16)$ \\
\hline $\begin{array}{l}\text { Median } \\
\text { odds ratio }\end{array}$ & 1.25 & 1.21 & 1.32 & 1.39 & 1.40 & 1.47 \\
\hline $\begin{array}{l}\text { Note: } \mathrm{Cl}= \\
\text { *Light gray } \\
\text { adjusted lik } \\
\text { expected } \mathrm{m} \\
\text { †Adjusted } \mathrm{f}\end{array}$ & $\begin{array}{l}\text { shows trauma cer } \\
\text { of death compared }\end{array}$ & $\begin{array}{l}\text { rain injury. } \\
\text { upper limits of tt } \\
\text { other centres). }\end{array}$ & $\begin{array}{l}\text { nfidence interval } \\
\text { ding shows traur }\end{array}$ & $\begin{array}{l}\text { spital mortality rat } \\
\text { s with lower limits }\end{array}$ & $\begin{array}{l}\text { ver than expecte } \\
\text { onfidence interva }\end{array}$ & $\begin{array}{l}y \text {, i.e., lower } \\
\text { ificantly higher tha }\end{array}$ \\
\hline
\end{tabular}

Table 4: Differences in trauma centre-specific adjusted mortality rates, overall and among patient subgroups after excluding transfers, Ontario, 2005-2011*

\begin{tabular}{|c|c|c|c|c|c|c|}
\hline \multirow[b]{2}{*}{$\begin{array}{l}\text { Trauma } \\
\text { centre }\end{array}$} & \multirow{2}{*}{$\begin{array}{l}\text { Overall, adjusted } \dagger \\
\text { mortality rate } \\
(95 \% \mathrm{Cl})\end{array}$} & \multicolumn{5}{|c|}{ Patient subgroup, adjusted $†$ mortality rate $(95 \% \mathrm{Cl})$} \\
\hline & & Shock $\ddagger$ & $\begin{array}{l}\text { Penetrating } \\
\text { truncal injury }\end{array}$ & $\begin{array}{l}\text { Blunt multisystem } \\
\text { injury }\end{array}$ & Older ( $\geq 65$ yr) & $\begin{array}{c}\text { Isolated severe } \\
\text { TBI }\end{array}$ \\
\hline 1 & $0.59(0.45-0.77)$ & $\mathrm{n} / \mathrm{a}$ & $1.09(0.84-1.40)$ & $0.67(0.49-0.92)$ & $0.60(0.42-0.85)$ & $0.40(0.27-0.61)$ \\
\hline 2 & $0.69(0.49-0.96)$ & $\mathrm{n} / \mathrm{a}$ & $0.99(0.75-1.30)$ & $0.77(0.47-1.24)$ & $0.54(0.35-0.82)$ & $0.69(0.44-1.08)$ \\
\hline 3 & $0.98(0.73-1.32)$ & $\mathrm{n} / \mathrm{a}$ & $0.97(0.74-1.27)$ & $1.19(0.80-1.76)$ & $1.05(0.73-1.50)$ & $1.05(0.71-1.56)$ \\
\hline 4 & $1.15(0.81-1.54)$ & $\mathrm{n} / \mathrm{a}$ & $1.00(0.76-1.31)$ & $0.87(0.55-1.36)$ & $1.14(0.77-1.69)$ & $0.13(0.73-1.74)$ \\
\hline 5 & $0.83(0.63-1.10)$ & $\mathrm{n} / \mathrm{a}$ & $0.98(0.76-1.27)$ & $0.87(0.61-1.24)$ & $0.82(0.57-1.18)$ & $0.91(0.62-1.33)$ \\
\hline 6 & $1.26(0.97-1.63)$ & $\mathrm{n} / \mathrm{a}$ & $1.00(0.76-1.30)$ & $1.16(0.83-1.62)$ & $1.14(0.83-1.60)$ & $1.31(0.94-1.85)$ \\
\hline 7 & $1.37(1.05-1.80)$ & $\mathrm{n} / \mathrm{a}$ & $1.01(0.77-1.31)$ & $1.51(1.08-2.09)$ & $1.37(0.97-1.93)$ & $1.46(1.00-2.12)$ \\
\hline 8 & $1.12(0.80-1.53)$ & $\mathrm{n} / \mathrm{a}$ & $0.99(0.76-1.30)$ & $0.85(0.55-1.32)$ & $1.40(0.95-2.08)$ & $1.31(0.84-2.03)$ \\
\hline 9 & $1.42(1.08-1.87)$ & $\mathrm{n} / \mathrm{a}$ & $0.99(0.75-1.29)$ & $1.46(1.03-2.07)$ & $1.46(1.04-2.05)$ & $1.38(0.95-2.01)$ \\
\hline $\begin{array}{l}\text { Median } \\
\text { odds ratio }\end{array}$ & 1.26 & $\mathrm{n} / \mathrm{a}$ & 1.14 & 1.38 & 1.45 & 1.49 \\
\hline $\begin{array}{l}\text { Note: } \mathrm{Cl}=\text { cor } \\
\text { *Light grey sh } \\
\text { lower adjuste } \\
\text { higher than ex } \\
\text { † Adjusted for } \\
\ddagger \text { After excludi }\end{array}$ & $\begin{array}{l}\text { ice interval, } \mathrm{TBI} \text { = traur } \\
\text { highlights trauma cen } \\
\text { ihood of death compar } \\
\text { ed mortality). } \\
\text { ler, age, mechanism o } \\
\text { insfers, variance in the }\end{array}$ & $\begin{array}{l}\text { injury. } \\
\text { the upp } \\
\text { other c }\end{array}$ & $\begin{array}{l}\text { e } 95 \% \text { confidence i } \\
\text { ker shading shows }\end{array}$ & $\begin{array}{l}\text { I for in-hospital morta } \\
\text { a centres with lower I }\end{array}$ & $\begin{array}{l}\text { e was }<1 \text { (mortality } \\
\text { f the confidence int }\end{array}$ & $\begin{array}{l}r \text { than expected, i.e., } \\
>1 \text { (significantly } \\
\text { his model. }\end{array}$ \\
\hline
\end{tabular}


trauma centres. Improved cooperation and sharing of best practices among trauma centres may be the first step toward further reductions in trauma centre mortality.

\section{Limitations of this study}

Limited by the retrospective design of our study, we cannot rule out the potential effect of variability in referral patterns and, hence, variation in case mix, among centres on the study results. However, we attempted to adjust for measured differences in case mix and account for potential correlation of patient outcomes at different hospitals, in addition to adding an extra term to account for the random differences in trauma-related mortality among centres using a randomintercept multilevel model. Observed differences might reflect inconsistencies in data coding or data capture and not true differences in quality of care; however, data collection was standardized by the use of a specialized registry by all institutions during the study period. This software was customized based on input from Ontario's trauma centres and the Trauma Registry Advisory Committee, and it includes logic and edit checks to ensure data accuracy, consistency and completeness.

Underreporting of patients who arrive without signs of life in the emergency department, whether because of local injury patterns or prehospital care practices, might positively influence centre-specific mortality; however, we believe that this assumption had no impact on our analysis, as such patients were excluded. Finally, we acknowledge that the OTR-CDS captures data only on patients admitted to hospital with trauma centres; thus, our analysis of temporal trends in mortality may not be applicable to all injured patients in Ontario.

\section{Conclusion}

We observed significant improvement over time in the mortality of severely injured adult patients cared for at Ontario's trauma centres. However, considerable differences in trauma centre-specific mortality were observed. These differences were most pronounced in injured older patients and those with isolated traumatic brain injury. System-wide performance improvement initiatives should target these patient subgroups.

\section{References}

1. Table 102-0561: Leading causes of death, total population, by age group and sex, Canada. CANSIM database. Ottawa: Statistics Canada; 2012. Available: www5 .statcan.gc.ca/cansim/pick-choisir?lang=eng\&p2=33\&id=1020561 (accessed 2014 June 12).

2. The economic burden of injury in Canada. Toronto: SMARTRISK; 2009

3. Macpherson, AK, Schull, MJ, Manuel, D, et al. Injuries in Ontario: ICES atlas. Toronto (ON): Institute for Clinical Evaluation Sciences; 2005.

4. Girotti, M. Report of the trauma expert panel. Toronto (ON): Ministry of Health and Long-Term Care; 2006.

5. MacKenzie EJ, Rivara FP, Jurkovich GJ, et al. A national evaluation of the effect of trauma-center care on mortality. N Engl 7 Med 2006;354:366-78.

6. Mackenzie EJ, Rivara FP, Jurkovich GJ, et al. The impact of trauma-center care on functional outcomes following major lower-limb trauma. 7 Bone foint Surg Am 2008;90:101-9.

7. Shafi S, Nathens AB, Parks J, et al. Trauma quality improvement using riskadjusted outcomes. 7 Trauma 2008;64:599-604; discussion 604-6.

8. Cudnik MT, Sayre MR, Hiestand B, et al. Are all trauma centers created equally? A statewide analysis. Acad Emerg Med 2010;17:701-8.

9. Hemmila MR, Nathens AB, Shafi S, et al. The Trauma Quality Improvement Program: pilot study and initial demonstration of feasibility. 7 Trauma 2010;68:253-62.
10. Trauma system accreditation guidelines. 4th rev. Halifax: Trauma Association of Canada; 2011

11. Baker SP, O'Neill B, Haddon W Jr, et al. The injury severity score: a method for describing patients with multiple injuries and evaluating emergency care. 7 Trauma 1974;14:187-96.

12. Fingerhut LA, Warner M. The ICD-10 injury mortality diagnosis matrix. Inj Prev 2006;12:24-9.

13. Berbiglia L, Lopez PP, Bair L, et al. Patterns of early mortality after trauma in a neighborhood urban trauma center: can we improve outcomes? Am Surg 2013;79:764-7.

14. Haas B, Gomez D, Xiong W, et al. External benchmarking of trauma center performance: have we forgotten our elders? Ann Surg 2011;253:144-50.

15. Newgard CD, Fildes JJ, Wu L, et al. Methodology and analytic rationale for the American College of Surgeons Trauma Quality Improvement Program. 7 Am Coll Surg 2013;216:147-57.

16. Kilgo PD, Osler TM, Meredith $W$. The worst injury predicts mortality outcome the best: rethinking the role of multiple injuries in trauma outcome scoring. 7 Trauma 2003;55:599-606; discussion 606-7.

17. Merlo J, Chaix B, Ohlsson H, et al. A brief conceptual tutorial of multilevel analysis in social epidemiology: using measures of clustering in multilevel logistic regression to investigate contextual phenomena. 7 Epidemiol Community Health 2006;60:290-7.

18. Clark DE, Hannan EL, Wu C. Predicting risk-adjusted mortality for trauma patients: logistic versus multilevel logistic models. 7 Am Coll Surg 2010;211: 224-31.

19. DeLong ER, Peterson ED, DeLong DM, et al. Comparing risk-adjustment methods for provider profiling. Stat Med 1997;16:2645-64.

20. Newgard CD, Haukoos JS. Advanced statistics: missing data in clinical research - part 2: multiple imputation. Acad Emerg Med 2007;14:669-78.

21. Nathens AB, Rivara FP, MacKenzie EJ, et al. The impact of an intensivistmodel ICU on trauma-related mortality. Ann Surg 2006;244:545-54.

22. Lenartowicz M, Parkovnick M, McFarlan A, et al. An evaluation of a proactive geriatric trauma consultation service. Ann Surg 2012;256:1098-101.

23. Fallon WF Jr, Rader E, Zyzanski S, et al. Geriatric outcomes are improved by a geriatric trauma consultation service. $\mathcal{F}$ Trauma 2006;61:1040-6.

24. Thompson HJ, Rivara FP, Jurkovich GJ, et al. Evaluation of the effect of intensity of care on mortality after traumatic brain injury. Crit Care Med 2008; 36:282-90.

25. Nathens AB, Rivara FP, Wang J, et al. Variation in the rates of do not resuscitate orders after major trauma and the impact of intensive care unit environment. 7 Trauma 2008;64:81-8, discussion 88-91.

26. Richardson DK, Zive DM, Newgard CD. End-of-life decision-making for patients admitted through the emergency department: hospital variability, patient demographics, and changes over time. Acad Emerg Med 2013;20:381-7.

Affiliations: Department of Surgery and Division of General Surgery (Gomez, Tien, Nathens), University of Toronto, Toronto, Ont.; Sunnybrook Research Institute (Gomez, Alali, Haas, Xiong, Tien, Nathens), Sunnybrook Health Sciences Centre, Toronto, Ont.; Institute of Health Policy, Management and Evaluation (Alali), University of Toronto, Toronto, Ont.; Interdepartmental Division of Critical Care (Haas), University of Toronto, Toronto, Ont.

Contributors: David Gomez and Avery Nathens were responsible for conception and design of this study. David Gomez, Aziz Alali and Wei Xiong were responsible for acquisition of data. David Gomez, Aziz Alali, Barbara Haas, Wei Xiong, Homer Tien and Avery Nathens were responsible for analysis and interpretation of data. David Gomez, Aziz Alali, Barbara Haas and Avery Nathens drafted the manuscript. David Gomez, Aziz Alali, Barbara Haas, Wei Xiong, Homer Tien and Avery Nathens reviewed the manuscript critically. David Gomez, Aziz Alali, Barbara Haas, Wei Xiong, Homer Tien and Avery Nathens gave final approval of the manuscript. All authors agreed to act as guarantors of the work.

Funding: This work was supported in part by funds from the Canada Research Chair Program (Avery Nathens).

Supplemental information: For reviewer comments and the original submission of this manuscript, please see www.cmajopen.ca/content /2/3/E176/suppl/DC1

Editor's statement: To promote transparency, CMAJ Open publishes the names of public institutions in research papers that compare their performance or quality of care with other institutions. The authors of this paper have not linked individual institutions to outcome data. We decided to publish this paper without this information, as we felt that it was more important to communicate the finding that variation exists between institutions in decisions about care of patients admitted to hospital for trauma than to insist on transparency. 